\title{
Bacillary necrosis in farmed Pangasius hypophthalmus (Sauvage) from the Mekong Delta, Vietnam
}

\author{
H W Ferguson ${ }^{1}$, J F Turnbull ${ }^{1}$, A Shinn ${ }^{1}$, K Thompson ${ }^{1}$, T T Dung ${ }^{2}$ and M Crumlish ${ }^{1}$ \\ 1 Institute of Aquaculture, University of Stirling, Scotland \\ 2 Department for Freshwater Aquaculture, College of Agriculture, CanTho, Vietnam
}

\begin{abstract}
This is the first description of an economically important disease of intensively reared Pangasius hypophthalmus from the Mekong Delta. Major presenting signs included an increase in mortality that would not respond to treatment, and at necropsy, the presence of numerous white necrotic and pyogranulomatous foci throughout the viscera, notably in spleen, liver and kidney. Despite the confounding presence in earlier samples of numerous, primarily renal, myxosporean parasites, the common denominator amongst these and samples from eight subsequently sampled sites was the presence of moderate-to-large numbers of bacilli in all typical lesions. These bacteria were subsequently isolated and tentatively identified as a Bacillus sp. Pilot studies experimentally reproduced similar lesions approximately 7 days following intraperitoneal injection of the bacteria.
\end{abstract}

Keywords: Bacillus sp., Pangasius hypophthalmus, pathology, Vietnam.

\section{Introduction}

Pangasius spp. are frequently cultured in freshwater systems throughout the Mekong Delta (Cacot 1999). In Vietnam, P. hypophthalmus (Sauvage) is common both in large cages (monoculture) and in smaller, family-unit sized ponds (mono and polyculture). It is sold locally on the domestic market or used for family consumption. Pangasius bocourti

Correspondence DrM Crumlish, Institute of Aquaculture, University of Stirling, Stirling FK9 4LA, UK

(e-mail: mc3@stir.ac.uk)
(Sauvage) is also grown in cage systems but is destined mainly for export to European markets (Singh 1990). There is little available published information about systemic diseases of farmed Pangasius spp. Aeromonads, notably Aeromonas hydrophila, are the significant pathogens noted in the literature (Thanh Hung, Subagja, Slembrouck \& Legendre 1998; Subagja, Slembrouck, Hung $\&$ Legendre 1999).

During routine examination of farmed $P$. hypophthalmus submitted to a diagnostic laboratory from two locations in Vietnam, a diagnosis was established of a disseminated severe multi-focal necrotizing and granulomatous bacterial infection, with a range of concurrent parasitic infections, mostly myxosporean. A follow-up survey of fish with similar clinical disease in eight different sites, which included a limited number of $P$. bocourti, confirmed this systemic bacterial infection as the primary, and sometimes the only disease in $P$. hypophthalmus, but not in $P$. bocourti. This preliminary paper describes the pathology of the condition and provides early bacteriological findings in an attempt to define this disease which we call 'bacillary necrosis'.

\section{Materials and methods}

\section{Clinical history}

The first group of samples (Batch 1) comprised nine $P$. hypophthalmus. Three fish were brought to the diagnostic laboratory by a farmer worried about higher-than-acceptable mortality. The other six were submitted from another farm for similar reasons, although in this latter case, three fish were considered to be disease-free controls. The lesions found in these fish prompted a more detailed investigation. Accordingly, the second group of 
sampled fish (Batch 2) was from eight different sites from various parts of the country (Fig. 1) and included both $P$. hypophthalmus and $P$. bocourti, as both species are found in the same geographical locations, although they are farmed separately. Once again, samples comprised fish from farms with higher-than-acceptable mortalities that had not responded to treatment.

\section{Pathology}

Fish were killed by anaesthetic overdose using 10\% $(\mathrm{w} / \mathrm{v})$ benzocaine solution (Sigma, Poole, Dorset, UK). Samples from kidney, spleen, liver, gills, muscle and skin were taken and fixed in 10\% buffered formalin for routine processing to paraffin wax sections. These were stained with haematoxylin and eosin ( $\mathrm{H} \& \mathrm{E})$, although selected sections were also stained with Gram's stain, Giemsa and ZiehlNeelsen.

\section{Bacteriology}

Samples of the liver, kidney and spleen were taken aseptically and plated directly onto tryptone soya agar (TSA, Becton Dickinson, Oxford, UK) plates. These were then incubated at $15-37^{\circ} \mathrm{C}$ and colonies observed after $24 \mathrm{~h}$ incubation. The predominant colony was sub-cultured to pure growth and held on TSA slopes for later identification using primary tests (Gram stain, shape, motility, oxidation/fermentation, oxidase, and temperature preferences) and secondary biochemical tests (API 20E kit, Biomeureux, Basingstoke, UK).

\section{Results}

\section{Pathology}

Clinically sick fish were emaciated, and several had a swollen abdomen and petechial haemorrhages on the tail, fins, and sometimes over the rest of the body. Internally, white $1-3 \mathrm{~mm}$ diameter miliary lesions were observed under the capsular surface and throughout the parenchyma in the liver, kidney and spleen of diseased fish. On cut surface the muscle appeared yellow, often with petechial haemorrhages. The gills were pale and viscous because of the presence of increased mucus.

\section{Histopathology}

Lesions in Batch 1 fish involved kidney, liver and spleen, with a few multi-focal lesions in muscle. Renal lesions were characterized by severe, acute to sub-acute multiple focally extensive areas of necrosis, progressing to pyogranulomatous lesions (Fig. 2). The lesions were centred primarily on

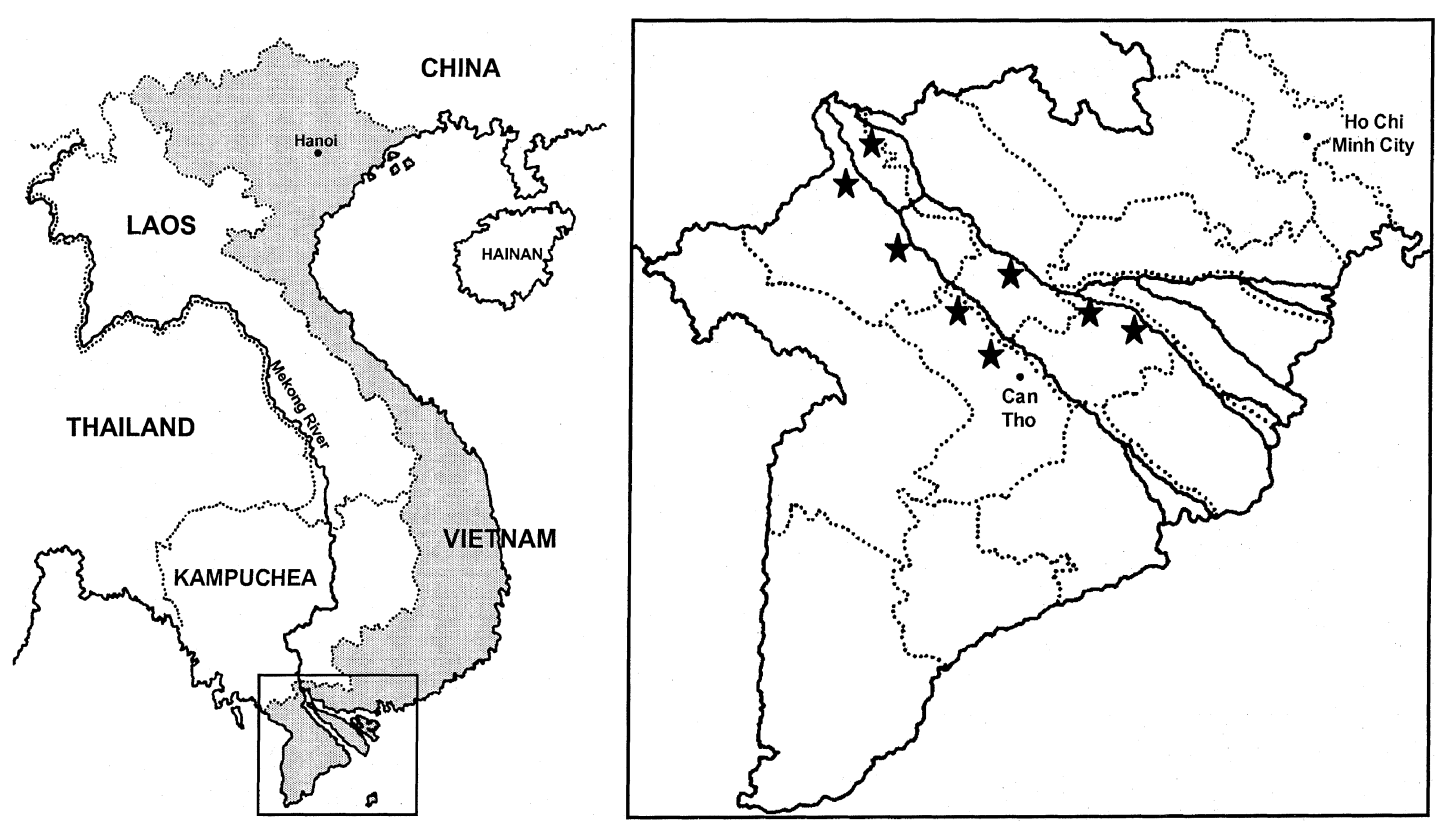

Figure 1 Map of Vietnam showing area involved. *Sampling sites. 


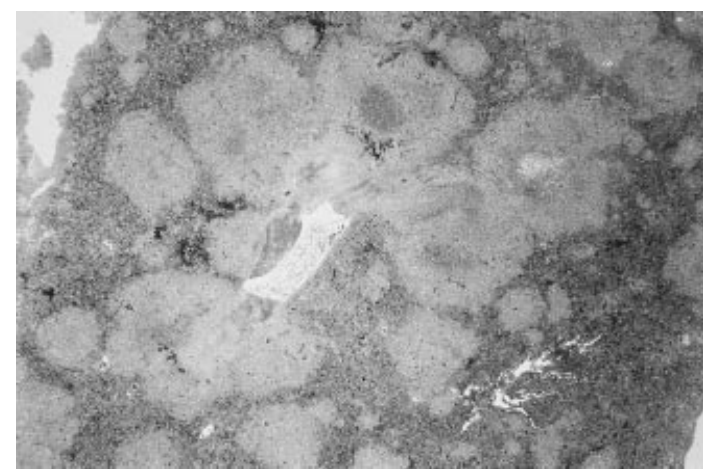

Figure 2 Spleen from $P$. hypophthalmus showing focally-extensive to confluent areas of necrosis within parenchyma $(\mathrm{H} \& \mathrm{E}$, $\times 15)$.

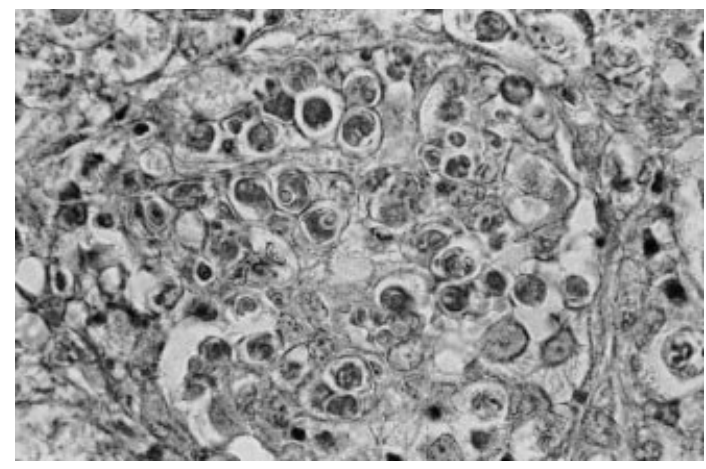

Figure 3 Kidney from $P$. hypophthalmus showing numerous Myxobolus-like myxosporeans within glomerulus, virtually obliterating normal architecture $(\mathrm{H} \& \mathrm{E}, \times 350)$.

the interstitium, but they extended out to encompass surrounding tubules which had varying degrees of degeneration and necrosis. These lesions were present in all six clinically sick fish from both sites, and even in one of the apparently clinically healthy fish. In all nine fish there were also varying degrees of nephrosis, tubular necrosis, and glomerulonephritis associated with various prespore and sporulated Myxobolus- and Sphaerospora-like myxosporean parasites (Fig. 3). Similar severe acute to sub-acute multi-focal areas of necrosis were also present in the spleen and liver of most fish, except for two from the clinically healthy group. Muscle lesions were characterized by the presence of a few small aggregates of microsporidian or myxosporean spores accompanied by limited inflammation.

Associated with the necrotic lesions in kidney, spleen and liver, were moderate to large numbers of medium-to-long bacilli, usually situated around the periphery, and often aggregated together into

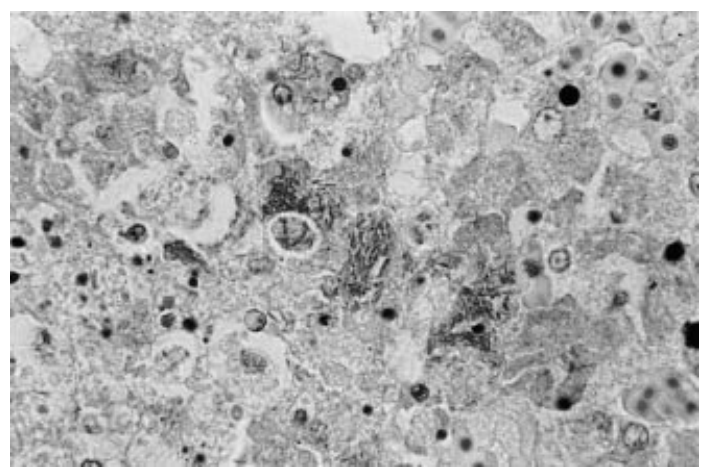

Figure 4 Liver from $P$. hypophthalmus showing clump of bacilli at margin of lesion (Gram stain, $\times 350$ ).

bundles, giving the appearance of being intracellular (Fig. 4). Special-stained sections showed that the bacteria were Gram-negative and non acid-fast, and although visible on $\mathrm{H} \& \mathrm{E}$ sections, they were most easily observed on special-stained sections.

Based on the above, it was felt that the multifocal necrosis was the most significant lesion, and that the disease, therefore, was primarily bacterial. There was little doubt, however, that the parasites, especially the renal myxosporea, were also having a significant effect on the fish.

Lesions in Batch 2 fish were very similar in $P$. hypophthalmus from all eight sites. Little of significance was found in $P$. bocourti, even in clinically 'sick' fish. In affected $P$. hypophthalmus, however, diagnosis was more clear-cut than in Batch 1 fish. Yet again the main lesion was acute severe multi-focal necrosis in kidney, spleen and liver, but this time there was much less complication of the overall picture because of concurrent disease, especially myxosporeans; this was particularly true for the visceral organs. Some 'sick' $P$. hypophthalmus did have mild to moderate gill disease (multi-focal branchial lamellar epithelial hyperplasia and fusion), associated with monogeneans, trichodinids and Myxobolus-like myxosporeans, but there was no obvious difference in severity between those fish adjudged to be clinically healthy and those adjudged clinically to be sick. Consequently, the gill lesions were considered to be of reduced significance. Out of a total of 43 fish examined, there was disagreement in five cases between the clinical assessment and the pathological findings. In one case, a $P$. hypophthalmus that was judged to be healthy turned out to have severe lesions, while in four others (three of which were $P$. bocourti), the converse was true, but with no 
satisfactory alternative explanation for their clinical condition. Overall the lesions in P. hypophthalmus were very similar to those encountered in Batch 1 , but were mostly acute multi-focal necrosis, with less obvious progression to granulomatous inflammation. Kidney and spleen tended to be more often and more severely affected than liver; indeed in some fish, lesions were very large, virtually completely obliterating normal architecture. Large early thrombi were sometimes seen in major vessels. Once again, bacteria morphologically identical to those seen in Batch 1 fish were much in evidence throughout all lesions in all organs.

\section{Bacteriology}

Bacterial colonies were $1 \mathrm{~mm}$ in diameter and cream when grown on TSA for $24 \mathrm{~h}$ at $28{ }^{\circ} \mathrm{C}$. They were Gram-variable, long slender bacilli, motile, weakly oxidase positive, and had no reaction with sugars (O/F, Becton Dickinson, Oxford, UK). Positive enzymatic reactions were found only for the production of hydrogen sulphide and gelatinase when tested using the API 20E-identification-kit. The bacteria grew at a temperature range from 15 to $37^{\circ} \mathrm{C}$ on TSA, but optimal growth was found between 28 and $37^{\circ} \mathrm{C}$. The bacteria could not be identified. The closest match was Bacillus fumarioli with $95 \%$ confidence using $16 \mathrm{~S}$ rRNA analysis from Genebank (MIDI Laboratories, Delaware, USA).

\section{Discussion}

Although the results are clearly preliminary, on the basis of the findings from these two separate batches of submissions, totalling 10 farms in all, it seems reasonable to suggest that this disease has a bacterial aetiology. Accordingly we are naming this condition 'bacillary necrosis of Pangasius'. The disease was not seen in $P$. bocourti, only in $P$. hypophthalmus. We do not know if this is the result of a difference in species susceptibility, of some variation in husbandry practices, or merely the result of insufficient sample size. This is obviously an area that demands further investigation, as it may have a major impact on choosing which species to farm.

The only isolate that resembled the morphology of the bacteria in sections was identified as a Bacillus sp., with a $95 \%$ similarity to $B$. fumarioli, an endospore-forming soil-inhabiting bacterium encountered in geothermal environments in various parts of the world including the South Sandwich archipelago and Antarctica (Logan, Lebbe, Hoste, Goris, Forsyth, Heyndrickx, Murray, Syme, WynnWilliams \& De Vos 2000). Much more work is needed on characterizing the isolates and establishing their precise role in the pathogenesis of the disease, but pilot studies $\left(2 \times 10^{7}\right.$ organisms injected intraperitoneally) have already shown that the bacteria will reproduce morphologically similar lesions in experimentally inoculated fish. We can find no records in the literature of other Bacillus spp. causing systemic disease in fish although $B$. mycoides will cause dermal ulceration (Goodwin, Roy, Grizzle \& Goldsby 1994). Bacillus anthracis is responsible for anthrax in man and other mammals (Mesolson, Guillemin, Hugh-Jones, Langmuir, Popova, Shelokov \& Yampolskaya 1994) and B. cereus is associated with food-poisoning and other syndromes in man. Some Bacillus spp. are used as growth promoters in the aquatic environment, while the toxins of the soil-inhabiting $B$. thuringiensis are used in insect control (Entwistle, Cory, Bailey \& Higgins 1993). The ability of our isolates to thrive in vitro at $37^{\circ} \mathrm{C}$, and possibly beyond, raises the disturbing possibility that they may have zoonotic potential. Certainly the type of aquaculture practised on the Mekong, with animal and human effluent deliberately used to fertilize the receiving waters, lends itself very well to the promotion of cross-species transfer.

There are several systemic bacterial infections in fish that usually present as chronic granulomatous disease, but under some circumstances can present as acute necrosis, the type of host response and presentation seemingly dependent on accompanying environmental or other stress factors. Examples include pasteurellosis (Photobacterium damsela subsp. piscicida), bacterial kidney disease (Renibacterium salmoninarum), and even mycobacteriosis (Ferguson 1989). In this investigation there seems little doubt that the concurrent parasitic disease, notably the renal myxosporean infection(s), could have had a considerable debilitating effect in some individuals, and would have contributed substantially to the clinical picture overall. Indeed in many cases their presence may have been responsible for some of the variation in inflammatory response noted between Batch 1 and Batch 2 fish. Nevertheless, the overriding common finding was the bacterial-associated necrosis, and it is the consequences of these lesions that should probably direct investigations into the cause of death in these animals. The relative importance of the 
interstitial and tubular components of the renal lesions with regard to immune responsiveness and osmoregulation respectively, and the significance of the thrombosis in relation to possible toxin release and terminal disseminated intravascular coagulation, are all avenues that remain to be explored.

\section{Acknowledgments}

We would like to thank DFID for financial support, and the College of Agriculture, Can Tho, Vietnam.

\section{References}

Cacot P. (1999) Etude du cycle sexuel et maitrise de la reproduction de Pangasius bocourti. (Sauvage, 1880) et Pangasius hypophthalmus (Sauvage, 1878) dans le delta due Mekong au Viet-Nam. PhD Thesis, CanTho University, Vietnam.

Entwistle P.F., Cory J.S., Bailey M.J. \& Higgins S. eds (1993) Bacillus thuringiensis, An Environmental Biopesticide: Theory and Practice. John Wiley \& Sons, New York, USA.

Ferguson H.W. (1989) Systemic Pathology of Fish. A Text and Atlas of Comparative Tissue Responses in Diseases of Teleosts. Iowa State University Press, Ames, Iowa, USA.

Goodwin A.E., Roy J.S., Grizzte J.M. \& Goldsby M.T. (1994) Bacillus Mycoides- a bacterial pathogen of channel catfish. Diseases of Aquatic Organisms 18, 173-179.
Logan N.A., Lebbe L., Hoste B., Goris J., Forsyth G., Heyndrickx M., Murray B.L., Syme N., Wynn-Williams D.D. \& De Vos P. (2000) Aerobic endospore-forming bacteria from geothermal environments in northern Victoria Land, Antarctica, and Candlemas Island, South Sandwich archipelago, with the proposal of Bacillus fumarioli sp. nov. International Journal of Systematic and Evolutionary Microbiology 50, 1741-1753.

Mesolson M., Guillemin J., Hugh-Jones M., Langmuir A., Popova I., Shelokov A. and Yampolskaya O. (1994) The Sverdlovsk anthrax outbreak of 1979. Science 266, 1202-1208.

Singh S.B. (1990) Status of aquaculture in the Socialist Republic of Vietnam. In: Aquaculture in Asia (ed. by M.M. Joseph), pp. 371-384. Asian Fisheries Society, Indian Branch, Mangalore.

Subagja J., Slembrouck J., Hung L.T. \& Legendre M. (1999) Larval rearing of an Asian catfish Pangasius hypophthalmus (Siluroidei Pangasiidae): analysis of precocious mortality and proposition of appropriate treatments. Aquatic Living Resources $12,37-44$.

Thanh Hung Le., Subagja J., Slembrouck J. \& Legendre M. (1998) Study on mass mortality of Pangasius hypophthalmus during larval rearing and its control and prevention. Abstract 27, National Workshop on Aquaculture, September 29-30, 1998, Bac Ninh, Vietnam.

Received: 27 February 2001

Accepted: 10 May 2001 